\title{
Biografía
}

\section{“Dr. Alfonso Acosta Guzmán: una mente brillante"}

De los cientos de profesionales que ha tenido el país, comparativamente muy pocos han dejado huellas más allá de su círculo inmediato. En la historia de la medicina costarricense hay colegas que han plasmado una huella indeleble, por su manera de actuar y pensar, y que con una mente inquieta han incursionado en caminos que no habían sido recorridos, logrando sobresalir en su creatividad, y uno de ellos es, sin duda, el Dr. Alfonso Acosta Guzmán.

Nació en San José el 8 de septiembre de 1905, hijo del licenciado Adán Acosta Valverde, quien fue uno de los abogados más prominentes de la época, y de doña Esther Guzmán Quirós. Realizó sus estudios primarios en las escuelas Juan Rafael Mora Porras y Juan Rudín. Obtuvo su bachillerato en Ciencias y Letras en el Liceo de Costa Rica, en 1922.

En 1923 marchó hacia Alemania para estudiar Medicina en la Rheinische Friedrich-Wilhelms-Universität, en Bonn, donde se graduó como doctor en Medicina en 1928. Conocedor de que desde 1894 en Costa Rica existían leyes atinentes a la intervención del médico como asesor de la justicia, su inquietud y aptitud para aprender lo motivó además a cursar asignaturas especiales durante las vacaciones universitarias en el Instituto Médico Legal de Bonn, bajo la dirección del profesor Müller -Hess, en 1926. También estudió durante las vacaciones de 1927, en el Instituto de Enfermedades Navales y Tropicales de Hamburgo, con la dirección, entre otros, de los profesores Mühlens y Giemsa. Hizo tres semestres fuera de Bonn, en las escuelas de Medicina de Viena, Colonia y Dusseldorf. Fue interno en las clínicas de Bonn y Colonia en 1926 y 1927.

Durante 1928 se desempeñó como asistente de cirugía en el hospital Santa Elizabeth, de Bochum-Westfalia, y en diciembre de ese mismo año se incorporó, mediante examen, a la Facultad de Medicina de Costa Rica (institución antecesora al Colegio de Médicos y Cirujanos de Costa Rica), correspondiéndole el código 31, e ingresó como interno residente en Cirugía en el Hospital San Juan de Dios.

Los años de estudiante le habían inculcado no solo su afición a la música, sino el deseo de construir en Costa Rica organismos que ya en Europa habían tomado forma con estructuras de innegable rendimiento. Fue incluso el primero que pensó en el seguro social como entidad organizada, capaz de prestar servicios a las clases obreras.

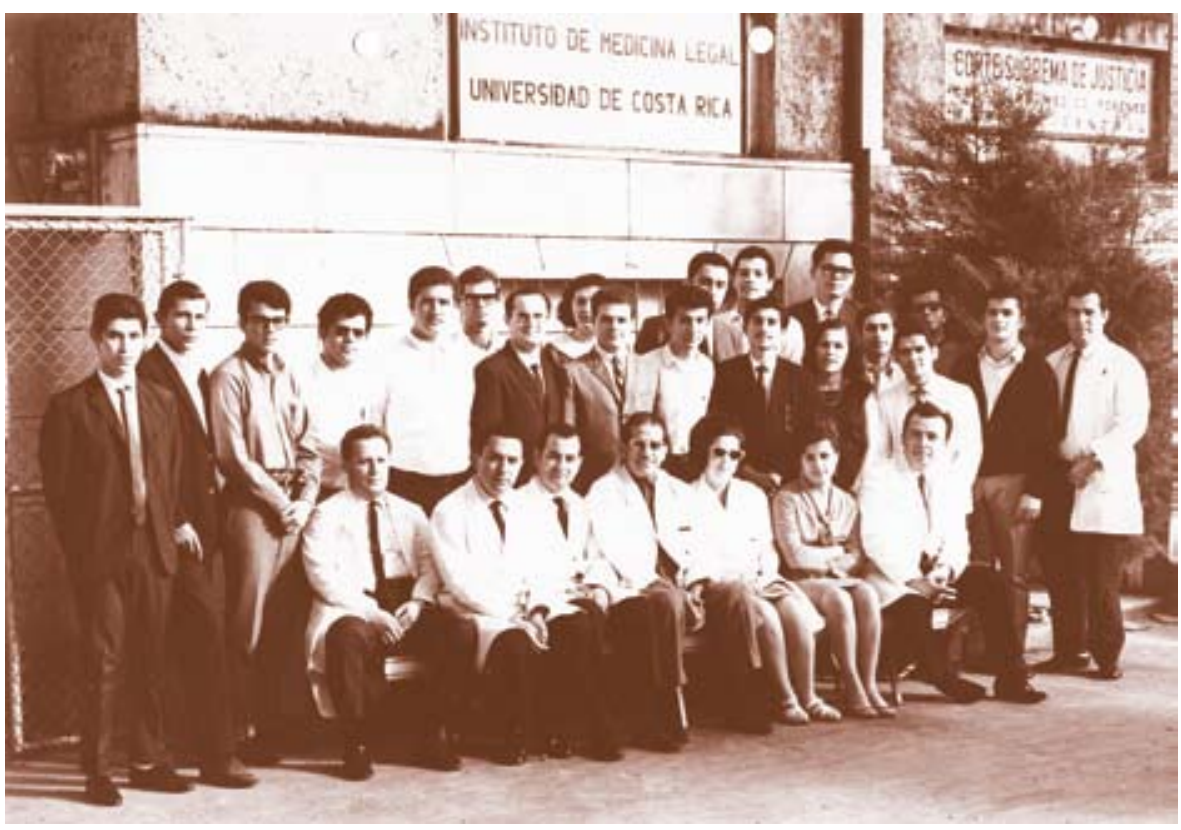

Dr. Alfonso Acosta Guzmán, junto con los primeros docentes y estudiantes de la cátedra de medicina legal en 1965. En las leyendas se aprecia en primer plano "Instituto de Medicina Legal" y "Universidad de Costa Rica" y en el segundo plano "Corte Suprema de Justicia y "Organismo Médico Forense" 
Para aquel momento, el Colegio de Abogados había aprobado, el 7 de mayo de 1928, la propuesta del licenciado Alejandro Alvarado Quirós, entonces presidente del Colegio, de crear una cátedra de Medicina Legal en la Escuela de Derecho, que era dependencia de la Junta Directiva del Colegio de Abogados. Esta Cátedra inició labores en 1929, fungiendo como profesor el Dr. Acosta Guzmán (una lección diaria en el quinto año de la carrera), y contó entre sus alumnos con quienes llegarían a ser juristas destacados en la historia nacional. Fue entonces cuando el Dr. Acosta observó la necesidad de un libro de texto sobre Medicina Legal, y como no había ninguno en el país, decidió escribirlo. En 1932 ese texto ya existía, tales eran su convicción y capacidad. Ese libro llegó a publicarse hasta su cuarta edición, esta última en dos tomos (1969-1970), cada una de ellas corregida y ampliada, dependiendo de la evolución de los conceptos técnicos. En sus libros se encuentran temas relacionados con el derecho médico y enfermedades laborales, tratados de una manera brillante y a la luz de una sólida formación médico - legal alcanzada en el continente europeo (Cuadro 1).

A finales de 1931 concluyó su internado en el Hospital San Juan de Dios, desempeñándose como médico asistente desde 1931 a 1934, especialmente en los servicios de Obstetricia y Cirugía. También fue asistente en la Maternidad Carit en 1932. Y desde 1934 se desempeñó como asistente en el Servicio de Cirugía General.

De 1929a 1936 actuó como médicojefe del Departamento de Epidemiología de la Secretaría de Salubridad, del cual fue fundador, con los auspicios del ex secretario de Salubridad, Dr. Solón Núñez, y del Dr. Shapiro, médico de la Fundación Rockefeller.

Pero como persona de grandes iniciativas, su trabajo trascendió las áreas clínica y académica, y fue consciente de las necesidades del gremio médico al fungir como fiscal y secretario de la Junta de Gobierno de la Facultad de Medicina de Costa Rica, en 1932 y 1935, respectivamente.

Fue en 1935 cuando el Dr. Acosta Guzmán regresó a Alemania para especializarse en Medicina Legal, durante dos años. Y además fue delegado al Congreso Internacional para la Ciencia de la Población en Berlín, como médico epidemiólogo de la Secretaría de Salubridad Pública.

Con motivo de los Juegos Olímpicos de Berlín 1936, fue investido con el carácter de Ministro Plenipotenciario y Enviado Extraordinario ante el Gobierno de Alemania en misión especial. Fue huésped personal del Führer en Múnich, condecorado por méritos en su especialidad con la Gran Insignia de la Cruz Roja Alemana, la Cruz de Platino, y fue miembro de la Academia Médica Germano - Iberoamericana de Berlín, la cual le otorgó la honrosa designación de senador honorífico.
De regreso al país, continuó con la docencia y fue cirujano mayor del ejército, con el grado de Teniente Coronel, asimilado a Coronel de 1936 a 1939. Para entonces había estado casado dos veces: su primer matrimonio fue con Irma Kuhne, y en 1938 contrajo matrimonio con Emma Himmel Mechel, directora del Conservatorio de Múnich, con quien procreó a sus dos hijos: Sonia y Alfonso Acosta Himmel.

En 1939 el cuerpo médico costarricense recibió con beneplácito su nombramiento como nuevo Secretario de Estado en los despachos de Salubridad Pública y Protección Social, en el gobierno del presidente León Cortés Castro, ya que el Dr. Acosta gozaba de unánime simpatía entre sus colegas, por su trato afable y jovialidad reconocida; ese cargo lo ocupó hasta 1940. En octubre de 1939 presidió en San José el Congreso Panamericano Infantil, que incluyó temas de medicina, cirugía, higiene y eugenesia, educación, asistencia social y legislación y sociología, y fue reseñado por el British Medical Journal.

Fue jefe de Clínica del Servicio de Cirugía en el Hospital San Juan de Dios, desde 1940 hasta 1949. Además, tras la creación de la Caja Costarricense de Seguro Social, fue jefe de clínica del Servicio de Cirugía General del Hospital Central (actual Hospital Dr. Rafael Á. Calderón Guardia) desde fines de 1943 hasta 1948, y fue fundador y jefe de los servicios de Ginecología y Obstetricia del mismo hospital, de 1948 a 1964. Desde ahí se desplazaba hasta la Corte Suprema de Justicia para impartir sus lecciones de medicina legal.

Para 1942, su formación en Alemania lo hizo ser una víctima más de la xenofobia absurda y los intereses políticos, cuando tras la declaratoria de guerra a Alemania por parte del gobierno costarricense, la noche del 4 de julio de $1942 \mathrm{su}$ consultorio médico fue el primer local en ser apedreado por algún sujeto enardecido por el odio antinazi.

Fue presidente del Colegio de Médicos y Cirujanos de Costa Rica en 1950, cuando los partos institucionalizados eran solo un 20\%; la mortalidad infantil, de 95 por cada mil nacidos vivos; la esperanza de vida al nacer, de 55,6 años, y los médicos en el país 3,1 por diez mil habitantes. Este año coincidió además con la creación en el país del Consejo Técnico de Asistencia Médico Social, para planificar y coordinar la red hospitalaria, distribuir y fiscalizar recursos económicos, y supervisar instituciones de servicios hospitalarios privadas. Como presidente del Colegio de Médicos y Cirujanos, el Dr. Acosta fue miembro del cuerpo consultivo de la Revista Médica de Costa Rica, publicación mensual del Colegio de Médicos y Cirujanos y del Centro de Estudios Médicos "Moreno Cañas".

En 1958 la Universidad de Costa Rica lo declaró Licenciado en Derecho Honoris Causa, en reconocimiento a su encomiable labor en la formación de los juristas del país, 
su enseñanza en la aplicación de los conocimientos médicos a los procesos judiciales -que contribuyó al asesoramiento, perfeccionamiento y evolución de las leyes- y su profundo compromiso con valores ético - deontológicos, básicos del ejercicio profesional.

Como se ha comentado, la visión a futuro del Dr. Acosta estaba muy influida por sus vivencias en Europa, precisamente en Alemania, de donde se inspiró para llevar a cabo proyectos vanguardistas en su tiempo. Fue gracias a su inteligencia y empeño que logró hacer entender a la Corte Suprema de Justicia, que en el país se necesitaba un Instituto Médico Legal, el cual auxiliara a la administración de la justicia y mejorara todo lo relativo a la medicina forense costarricense. El Dr. Acosta Guzmán era tan claro de palabras y tan convincente, que además consiguió que fuera a su vez sede de la Cátedra de Medicina Legal de la incipiente Escuela de Medicina de la Universidad de Costa Rica. Ahí estaba parte de su actuar: el conocimiento y la honestidad propia, sin temor a la crítica con fe en su acción.

$\mathrm{Y}$ es que la docencia en la Escuela de Medicina de la Universidad de Costa Rica no se inició en 1953, al aprobarse la creación de la Escuela, sino años más tarde, lo que constituyó un período suficiente para madurar los planes de organización, adquirir el equipo y conseguir el entrenamiento del personal. Por ese motivo, en 1959 fue enviado por la Universidad de Costa Rica a Nueva Orleans y Maryland, para estudiar la fundación de la organización de la medicina legal en Costa Rica.

En 1961 se nombró al Dr. Acosta -mediante concursocomo profesor titular y director de la Cátedra de Medicina Legal, y fungió como miembro de la Comisión de Presupuesto. Para 1965, la docencia de medicina legal en la Escuela de Medicina ya había iniciado, y también debido al dinamismo emprendido por el Dr. Acosta, inició labores el Organismo Médico Forense de la Corte Suprema de Justicia, bajo su dirección desde el 1 de enero de 1965 hasta diciembre de 1973.

La creación del Organismo Médico Forense tuvo como sustento jurídico la Ley 3265, del 6 de febrero de 1964, cuya aprobación por la Asamblea Legislativa fue el resultado de la ardua labor del Dr. Acosta, a quien secundaron en una activa campaña editorial el patólogo Rodolfo Céspedes, desde la revista Acta Médica Costarricense, y el periodista Manuel Formoso, columnista del periódico La Nación. Para valorar lo trascendente de este hecho, debe considerarse que no existían instituciones similares en Centroamérica. En su organización sobresale la ubicación dentro de la estructura del Poder Judicial, para lo cual fue necesario -una vez emitida la Ley Constitucional- enviar al extranjero a especializarse a los tres profesionales básicos con los cuales comenzar a trabajar: el patólogo forense, el toxicólogo y el criminólogo, trabajo que contó con la colaboración del profesor Richard Muhling, "Coroner" del Departamento de Medicina Legal de Nueva Orleans, Luisiana.
En 1966, el Dr. Acosta publicó su libro "La enfermedad profesional", dedicado a los primeros médicos que se graduaron en Costa Rica.

Para 1969, apuntó la importancia de la discusión, actualización y difusión de los conocimientos médico legales, mediante un órgano que agrupara a profesionales del campo forense, y fue así como se convirtió en el miembro fundador y primer presidente de la Asociación Costarricense de Medicina Legal y Toxicología.

En el plano docente, el Dr. Acosta tuvo el honor de haber sido el primer profesor catedrático de Medicina Legal, hasta su jubilación en 1969, y en 1970 le fue otorgado el título de profesor emérito, máxima distinción a un docente en la Universidad de Costa Rica.

Coincidiendo con su jubilación en 1973, el Dr. Acosta publicó su libro autobiográfico: El esclavo libre, donde demuestra su grandeza personal, con conceptos que siguen vigentes en el quehacer médico; dedica sus páginas a los jóvenes costarricenses que tengan el propósito de estudiar Medicina y diserta partiendo de la diferencia de condiciones del profesional de Medicina en relación con cualquier otro, sobre su experiencia, en el sentido de que para ser médico es preciso llegar a ser uno que trabaje con el corazón en la mano y desprendido de todo materialismo, pues si los profesionales hubieran cambiado su área de estudio por cualquier otra, hubieran podido vivir una vida más tranquila o menos azarosa, a manera de metáfora, "la esclavitud del médico" dura lo que dure su vida.

En 1974 la estructura médico forense original, como la concibiese el Dr. Acosta Guzmán, fue modificada por ley, con la creación del Organismo de Investigación Judicial, que incorpora la medicina legal como un departamento independiente de las investigaciones criminales y laboratorios forenses; responsable de la formación de los médicos especialistas en el país continúa siendo sede de la Cátedra de Medicina Legal de la Universidad de Costa Rica. Este logro no hubiera sido posible sin los ideales, esfuerzo e iniciativa del Dr. Acosta Guzmán. Por su brillante labor como fundador y primer director del Organismo Médico Forense, en marzo de 1974, el Lic. Fernando Baudrit Solera, presidente de la Corte Suprema de Justicia y ex alumno suyo, le entrega un reconocimiento público y honorífico por parte del Poder Judicial.

El 2 de marzo de 1979, el Poder Judicial le rindió homenaje en ocasión de cumplirse el cincuentenario de la enseñanza formal de la medicina legal en Costa Rica. En esa oportunidad se colocó una placa conmemorativa en el Departamento de Medicina Legal, que deja constancia a las generaciones futuras, de su labor en el progreso de la investigación criminal en Costa Rica. La Dirección General de Correos emitió un sello postal alusivo a este hecho. 
La muerte lo sorprendió el 16 de agosto de 1985; su velación se efectuó en la Corte Suprema de Justicia y sus restos reposan en el mausoleo familiar, en el Cementerio General de San José.

El Dr. Acosta fue un hombre humilde con una mente brillante, un ciudadano que le dio cuanto pudo al país, sin sacar provecho personal de su posición y prestigio. Gracias a su trabajo visionario, hoy la medicina legal se ha consolidado como una especialidad médica de reconocido prestigio en el país: la pequeña Cátedra de Medicina Legal que inició labores en la Escuela de Medicina con cinco profesores, es ahora un departamento clínico que tiene un promedio semestral de más de quince profesores, quienes ejercen su labor en grado y postgrado con mística y compromiso con la docencia, la investigación y la acción social, con un plan de estudios revisado y actualizado en forma constante. $\mathrm{Y}$ el instituto médico forense que concibió el Dr. Acosta, con la actual estructura además apoya la formación en el campo médico legal de la Escuela Judicial, de otras universidades públicas y privadas que existen en el país, y de los programas de educación continua del Colegio de Médicos y Cirujanos de Costa Rica, a través de la Asociación Costarricense de Medicina Forense.

Por todos sus logros en el campo médico, que incidieron en una mejor salud y calidad de vida de la población y en el desarrollo profesional e institucional de Costa Rica, el 5 de febrero de 2010 el Colegio de Médicos y Cirujanos le realizó un homenaje póstumo, y actualmente está postulado por parte de la Corte Suprema de Justicia, para ser declarado Benemérito de la Patria.

\section{Dra. Grettchen Flores-Sandi}

Profesora Catedrática en Medicina Legal

Directora Departamento Clínico de Medicina Legal de la Escuela de Medicina

Universidad de Costa Rica

Correspondencia: grettchenflores@medicos.cr

\section{Lecturas recomendadas}

- Abarca C; Solano L. El esclavo libre: más que un libro. Med Leg Costa Rica 2005; 22:5-15.

- Abarca C; Solano L. Homenaje al Dr. Eduardo Vargas Alvarado. Med Leg Costa Rica 2003; 20:133-139.

- Acosta A. El esclavo libre. San José Costa Rica: Publicaciones de la Universidad de Costa Rica. 1973.

- Arias RF. Del protomedicato al Colegio de Médicos y Cirujanos: 145 años de historia. 2 ed. San José, Costa Rica: Porvenir, 2002. pág. 337.

- De La Cruz Y. La Escuela de Medicina de la Universidad de Costa Rica: Una reseña histórica. San José, Costa Rica: Oficina de Publicaciones de la Universidad de Costa Rica 1995.

- Duron, RA. Primer congreso nacional de patología y medicina forense en El Salvador. Revista Médica Hondureña 1966; 34: 12-14.

- Editorial. Los treinta años de la Morgue Judicial de Costa Rica. Med Leg Costa Rica 1995; 11: 2-3.

- Jaramillo J. Historia y filosofía de la medicina. San José: EUCR. 2005. Pág 243.

- Le dan fuego a Roma.... En: Villegas- Hoffmeister, G. La guerra de Figueres: Crónica de ocho años. San José Costa Rica: EUNED. 1998. Pag 44.

- $\quad$ Medical News. Br Med J 1939;2:627

- Memoria Colegio de Médicos y Cirujanos (1857-2008). 151 años de Historia de la Organización Médica en Costa Rica. San José, Costa Rica. MasterLitho, SA. Noviembre 2008. Pág. 216.

- Roldán J.M. Cátedra de Medicina Legal. Med Leg Costa Rica 1992; 9:41-42.

- Ugalde, J.G. La enseñanza del Derecho Médico en Costa Rica. Rev Latinoam Derecho Médico y Medicina Legal 1998; 3: 3-4.

- Vargas E. Datos biográficos: Dr. Alfonso Acosta Guzmán. Boletín Medicina Legal 1984; 1: 4.

- Vargas E. Editorial: El fallecimiento del maestro Acosta Guzmán. Med Leg Costa Rica 1985; 2:1

- Vargas E. Editorial: Los ochenta años del Dr. Alfonso Acosta Guzmán, Med Leg Costa Rica 1985; 2:1

- Zeledón J. El nuevo Secretario de Estado en los Despachos de Salubridad Pública y Protección Social. Revista Médica de Costa Rica 1939; 60: 487-488.

\begin{tabular}{|c|c|}
\hline \multicolumn{2}{|c|}{$\begin{array}{l}\text { Cuadro 1. Principales libros del Dr. Alfonso } \\
\text { Acosta Guzmán }\end{array}$} \\
\hline Año & Título \\
\hline 1932,1946 & "Medicina legal" y posteriormente \\
\hline 1961 у 1969. & "Medicina legal y toxicología" \\
\hline 1950 & "Obstetricia para enfermeras", \\
\hline 1952 & "Ginecología para enfermeras" \\
\hline 1964 & $\begin{array}{c}\text { "La enfermedad profesional" (alusivo a } \\
\text { las enfermedades laborales) }\end{array}$ \\
\hline 1973 & "El esclavo libre" (filosófico y motivador) \\
\hline
\end{tabular}

